\title{
The Antioxidant and Free Radical Scavenging Activities of Chlorophylls and Pheophytins
}

\author{
Ching-Yun Hsu ${ }^{1}$, Pi-Yu Chao ${ }^{2}$, Shene-Pin $\mathrm{Hu}^{3}$, Chi-Ming Yang ${ }^{4^{*}}$ \\ ${ }^{1}$ Department of Nutrition and Health Sciences, Chang Gung University of Science and Technology, Taoyuan, Taiwan; ${ }^{2}$ Department \\ of Food and Nutrition, Chinese Culture University, Taipei, Taiwan; ${ }^{3}$ School of Nutrition and Health Science, Taipei Medical Univer- \\ sity, Taipei, Taiwan; ${ }^{4}$ Biodiversity Research Center, Academia Sinica, Taipei, Taiwan. \\ Email: ${ }^{*}$ cmyang@gate.sinica.edu.tw
}

Received April $3^{\text {rd }}, 2013$; revised May $3^{\text {rd }}, 2013$; accepted May $12^{\text {th }}, 2013$

Copyright (C) 2013 Ching-Yun Hsu et al. This is an open access article distributed under the Creative Commons Attribution License, which permits unrestricted use, distribution, and reproduction in any medium, provided the original work is properly cited.

\begin{abstract}
Chlorophylls are important antioxidants found in foods. We explored the mechanisms through which the $\mathrm{a}$ and $\mathrm{b}$ forms of chlorophyll and of pheophytin (the Mg-chelated form of chlorophyll) reduce oxidation: we used comet assay to measure prevention of $\mathrm{H}_{2} \mathrm{O}_{2}$ DNA damage; we tested for quenching of 1,1-diphenyl-2-picrylhydrazyl (DPPH); we measured the ability to chelate $\mathrm{Fe}(\mathrm{II})$; and, we tested their ability to prevent formation of thiobarbituric acid reactive substances (TBARS) during Cu-mediated peroxidation of low density lipoprotein (LDL) in a chemical assay. All chlorophylls and pheophytins showed significant dose-dependent activity in the assays, with the pheophytins being the strongest antioxidants. Thus, these chemicals can prevent oxidative DNA damage and lipid peroxidation both by reducing reactive oxygen species, such as DPPH, and by chelation of metal ions, such as Fe(II), which can form reactive oxygen species.
\end{abstract}

Keywords: Chlorophyll; Pheophytin; Comet Assay; Antioxidation

\section{Introduction}

Epidemiological studies have connected diets high in vegetables with reduced cancer risks [1]. Chlorophylls and chlorophyll related compounds are among the best candidates for the chemicals responsible for the general protection afforded by vegetables. Chlorophyll compounds are highly abundant in green vegetables, and they have been shown to prevent carcinogenesis through multiple chemical mechanisms. Biological studies using purified chlorophyll compounds have been able to replicate some of the dietary benefits of eating green vegetables [2].

Chlorophyll is a photosensitive light harvesting pigment with special electronic properties. The general structure of chlorophyll (Figure 1) consists of a porphyrin ring chelating a $\mathrm{Mg}$ atom. A 20-carbon phytol tail at C17 makes the chlorophyll highly hydrophobic and allows chlorophyll to incorporate into biological lipid membranes. In the naturally occurring chlorophylls the functional group of $\mathrm{C} 7, \mathrm{a}-\mathrm{CH}_{3}$ or a $-\mathrm{CHO}$ group, define the a and $b$ forms of chlorophyll, respectively.

Naturally occurring a and $b$ derivatives of chlorophyll,

"Corresponding author. such as pheophytin, chlorophyllide, and pheophorbide, are present in plants as breakdown products [3], and in animals as the products of chlorophyll digestion [4]. The simplest derivative, pheophytin (Figure 1), has had the $\mathrm{Mg}$ atom dechelated from its porphyrin ring. A semisynthetically prepared chlorophyll derivative called chlorophyllin is commercially available. In commercial chlorophyllin, the $\mathrm{Mg}$ atom is replaced with a $\mathrm{Na}$ or $\mathrm{Cu}$ atom to form a water soluble, hydrophilic salt complex.

All the chlorophyll compounds act through similar anti-carcinogenic mechanisms, with varying degrees of strength. One proposed mechanism is that the chlorophyll porphyrin ring acts as an interceptor molecule, or desmutagen, by directly binding to other planar cyclic molecules through a shared pi-cloud [5-7]. Carcinogenic molecules with planar structures have been shown to be bound [7] and prevented from acting as carcinogens in biological systems [2,7-10]. However, other carcinogenic molecules are not directly bound by chlorophyll compounds, yet are still less effective as mutagens in the presence of chlorophyll compounds [7]. Possible additional anti-carcinogenic mechanisms include antioxidation $[5,11,12]$, chelation of pro-oxidant ions such as $\mathrm{Fe}(\mathrm{II})$ 

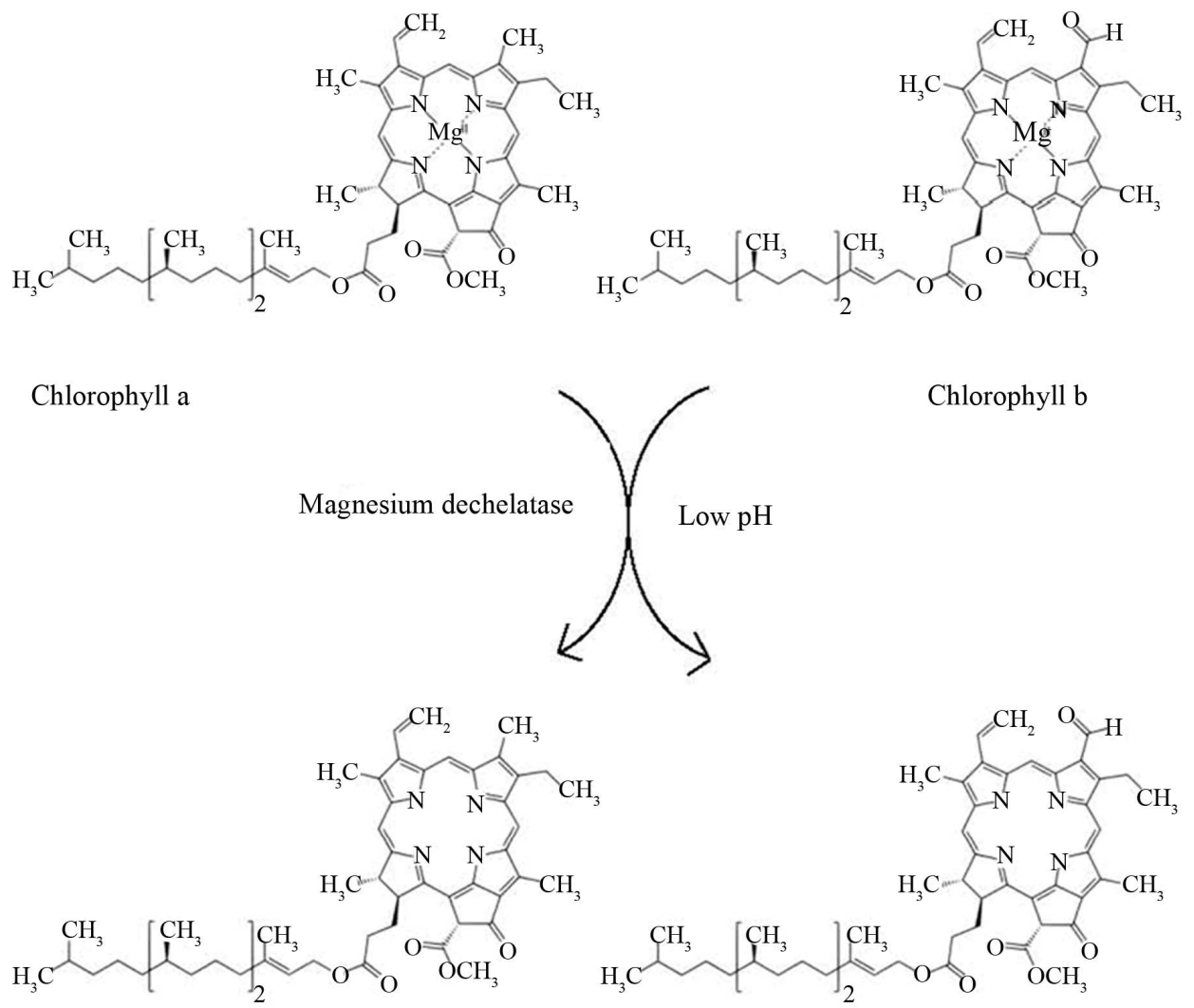

Pheophytin a

Pheophytin b

Figure 1. Structures of chlorophylls a and $b$ and pheophytins a and $b$.

$[13,14]$, or the stimulation of cellular defenses [15].

This paper presents data on the anti-oxidant and chelation properties of chlorophyll $\mathrm{a}$ and $\mathrm{b}$ and pheophytin $\mathrm{a}$ and $\mathrm{b}$ in relation to biological systems. Previous studies have shown that chlorophyll and pheophytin act as lipid antioxidants in stored edible oils [5], and can reduce free radicals in standard assays [5,11]. And, general protection from carcinogens by chlorophyllin has been observed in whole animal studies [2]. However, there is a gap between the mechanistically informative chemical studies and the biologically relevant assays regarding the nutritional antioxidant properties of chlorophylls.

Using chlorophyllins, pheophorbides, and chlorophylllides, we recently observed the reduction of free radicals and the protection of cultured human lymphocytes against oxidative DNA damage [12]. Here we study chlorophylls and pheophytins with respect to the protection of lymphocytes against oxidative DNA damage by $\mathrm{H}_{2} \mathrm{O}_{2}$, and explore whether they can act as direct reducers of free radicals or as chelators of $\mathrm{Fe}$ (II). We further test if the natural chlorophylls can prevent lipid peroxidation of lowdensity lipoprotein (LDL), as does the semisynthetic chlorophyllin $[13,14,16]$.

\section{Materials and Methods}

\subsection{Preparation of Chlorophyll and Derivatives}

Chlorophyll derivatives were prepared from spinach purchased in a local market in Taipei, Taiwan, as previously described [17]. Briefly, to extract chlorophylls a and b, spinach was washed with cold water, quickly freeze-dried, powdered in a mortar filled with liquid nitrogen, and stored at $-70^{\circ} \mathrm{C}$ until extraction. Total pigment was extracted from the powdered spinach by grinding in $80 \%$ acetone. The crude extract was centrifuged $(1500 \mathrm{~g}, 5$ $\mathrm{min})$. From the supernatant, chlorophyll a and $\mathrm{b}$ were purified by liquid chromatography using a combination of ion-exchange and size exclusion chromatography with a CM-Sepharose CL-6B column. Analyses of chromatography fractions were performed by measuring the absorbance at 663.6 and $646.6 \mathrm{~nm}$, which are the major absorption peaks of chlorophyll a and b. Chlorophyll a and $\mathrm{b}$ were further Mg-chelated to form pheophytin $\mathrm{a}$ and $\mathrm{b}$ by acidification with acetic acid.

\subsection{LDL Preparation}

Blood was drawn from the veins of healthy subjects and 
collected into sterile glass tubes containing $1.5 \mathrm{mg} / \mathrm{mL}$ EDTA-K3. Plasma was isolated immediately for preparation of LDL. A two-step LDL fraction $(1.006>\mathrm{d}>$ $1.063 \mathrm{~g} / \mathrm{mL}$ ) was isolated by two-step sequential flotation ultracentrifugation [18], using a Hitachi CP85 $\beta$ ultracentrifuge $\left(4^{\circ} \mathrm{C}, \mathrm{P} 70 \mathrm{AT} 2-376\right.$ rotor, $\left.44,000 \mathrm{rpm}\right)$ for $16 \mathrm{~h}(\mathrm{~d}$ $<1.006 \mathrm{~g} / \mathrm{mL})$ to remove VLDL and for $20 \mathrm{~h}(\mathrm{~d}<1.063$ $\mathrm{g} / \mathrm{mL}$ ) to collect LDL. The isolated LDL fraction from each study subject was dialyzed separately at $4^{\circ} \mathrm{C}$ against

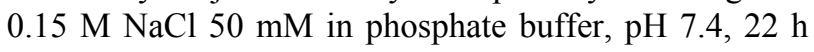
before use in the oxidative susceptibility of LDL assay.

Comet Assay. Blood samples $(10 \mathrm{~mL})$ were obtained from healthy donors, and lymphocytes were isolated using a separation solution kit (Ficoll-Paque Plus lymphocyte isolation sterile solution; Pharmacia Biotech, Sweden). For the experimental procedure, cells were harvested within one day of blood samples having been taken, and cultured in AIM V $\mathrm{V}^{\circledR}$ medium (serum-free lymphocyte medium; Invitrogen, Carlsbad, CA) in $5 \% \mathrm{CO}_{2} /$ $95 \%$ air, humidified, at $37^{\circ} \mathrm{C}$ for $24 \mathrm{~h}$.

Subsequent to culture, lymphocytes were exposed to one of the four different chlorophyll compounds at various concentrations for $30 \mathrm{~min}$ at $37^{\circ} \mathrm{C}$. All test substances were dissolved in dimethyl-sulfoxide (DMSO); the solvent concentration in the incubation medium never exceeded $1 \%$. Control incubations contained the same concentration of DMSO. Then, DNA damage was induced by adding $10 \mu \mathrm{M} \mathrm{H}_{2} \mathrm{O}_{2}$ for $5 \mathrm{~min}$ on ice. Treatment on ice minimizes the possibility of cellular DNA repair subsequent to $\mathrm{H}_{2} \mathrm{O}_{2}$ injury. Cells were centrifuged (100 g, $10 \mathrm{~min})$, washed, and resuspended in the same medium for the comet assay.

The comet assay [19] measures DNA single-strand break (ssbs) damage by fixing cells in soft agar on a microscope slide, subjecting them to electrophoresis, staining the DNA, and observing under a microscope. A tail of stained DNA is formed as it migrates out of the nucleus; the length of the tail of DNA is relative to the amount of DNA ssbs damage. We calculated tail moment, which increases as DNA damage increases. The assay was conducted as previously described [12]. Control tests with each of the components $\left(\mathrm{H}_{2} \mathrm{O}_{2}\right.$, chlorophyll compounds, DMSO) of the test alone were performed, and the tail moment by comet assay and viability by MTS assay were measured.

\subsection{Measurement of DPPH Radical Scavenging}

The ability of chlorophylls or pheophytins to scavenge free radicals was explored by their ability to reduce 1,1 diphenyl-2-picrylhydrazyl (DPPH) as previously described [12]. The DPPH scavenging capacity of chlorophyll or pheophytin was expressed as the percentage of inhibition by the following formula:

$$
\% \text { inhibition }=\left[\left(\mathrm{A}_{\text {control }}-\mathrm{A}_{\text {sample }}\right) / \mathrm{A}_{\text {control }}\right] \times 100
$$

where $A_{\text {control }}$ is the absorbance of the sample at $0 \mathrm{~min}$, and $\mathrm{A}_{\text {sample }}$ is the absorbance of the sample at 30 minutes.

\subsection{Chelation of Fe(II) Cation}

It has been proposed that most of the hydroxyl radicals in living organisms are due to iron ion-dependent generation through the Fenton reaction (ref). Following Dinis et al. [20], the binding of ferrous ions to chlorophylls or pheophytins was estimated by the decrease in the peak absorbance of the $\mathrm{Fe}(\mathrm{II})$-ferrozine complex. Briefly, 0 to $100 \mathrm{mM}$ of chlorophyll or pheophytin was incubated with $20 \mu \mathrm{M} \mathrm{Fe}$ (II) (ammonium ferrous sulfate) in 5\% ammonium acetate, $\mathrm{pH}$ 6.9. The reaction was initiated by the addition of $100 \mu \mathrm{M}$ ferrozine. After the mixture had reached equilibrium $(10 \mathrm{~min})$, the absorbance at $562 \mathrm{~nm}$ was measured. The chelating effect was calculated as:

$$
\begin{aligned}
& \% \text { chelating effect } \\
& =\left[1-\frac{\mathrm{A}_{562} \text { in the presence of sample }}{\mathrm{A}_{562} \mathrm{~nm} \text { in the absence of sample }}\right] \times 100
\end{aligned}
$$

\subsection{Antioxidant Activity in Human Low Density Lipoprotein (LDL) Oxidation System}

LDL oxidation was determined by measuring the amount of thiobarbituric acid reactive substances (TBARS). For assay of TBARS, the dialyzed LDL was diluted in saline to $0.9 \mathrm{mg} \mathrm{LDL}-\mathrm{C} / \mathrm{mL}$. LDL ( $50 \mathrm{~mL}$ in each assay tube) was incubated with $25 \mathrm{mM} \mathrm{CuSO}_{4}$ in the atmosphere at $37^{\circ} \mathrm{C}$ for $5 \mathrm{~h}$ to induce lipid peroxidation. The TBARS assay involved determining malonaldehyde (MDA) formation after peroxidation of LDL at intervals of $0,30,60$, $70,80,90,100,120,150,180,240$ and $300 \mathrm{~min}$. The incubation was terminated by adding $100 \mathrm{~mL}$ TCA $(15.2 \%$, $\mathrm{w} / \mathrm{v}$ ), and the mixture was cooled to $4^{\circ} \mathrm{C}$. A precipitate formed at the bottom of the tube, and a $100 \mathrm{~mL}$ aliquot of supernatant was taken for MDA assay [21]. The supernatant was added to $1 \mathrm{~mL}$ TBA solution $(0.6 \%, \mathrm{w} / \mathrm{v})$ and boiled at $100^{\circ} \mathrm{C}$ for at least $30 \mathrm{~min}$. Finally, 1, 1, 3, 3tetramethoxy propane was used as the source of MDA in the calibration of the TBARS assay. The assay was performed according to the procedure of Yagi [22] with modification. Pheophytin $\mathrm{a}$ and $\mathrm{b}$ and chlorophyll $\mathrm{a}$ and $\mathrm{b}$ were tested in this system. The control had no treatment. In addition, a known antioxidant, trolox, was measured with the assay. The TBA value was measured by its absorption at $532 \mathrm{~nm}$ wavelength. The percent inhibition of oxidation was calculated as:

$$
\% \text { inhibition }=\left[1-\frac{\text { TBA value of treated sample }}{\text { TBA value of control }}\right] \times 100
$$




\subsection{Statistical Analyses}

Data are reported as the mean \pm SD of triplicate determinations. Statistical analyses were performed using a Student's t-test to compare differences between control and pretreated groups. One-way ANOVA was used to test for differences amongst the chlorophyll compounds. Post hoc comparison of means was performed by Duncan's multiple comparison, and $\mathrm{p}<0.05$ was considered to represent a statistically significant difference between test populations.

\section{Results and Discussion}

In order to see if chlorophyll compounds act as antioxidants in a biological setting, we employed a comet assay to observe oxidative DNA damage caused by $\mathrm{H}_{2} \mathrm{O}_{2}$. As a preliminary, we check to see that chlorophyll, pheophytin or DMSO was non-toxic to the cells. The lymphocyte viability and DNA damage (tail moment) of cells treated with $\mathrm{H}_{2} \mathrm{O}_{2}$ alone, with chlorophylls $\mathrm{a}$ or $\mathrm{b}$ alone, with pheophytins $\mathrm{a}$ or $\mathrm{b}$ alone, with DMSO alone, or with nothing is shown in Table 1. We then tested to see if chlorophyll and pheophytins could act as antioxidants versus $\mathrm{H}_{2} \mathrm{O}_{2}$ in this system.

As expected, both chlorophyll compounds reduced the comet tail moment caused by $\mathrm{H}_{2} \mathrm{O}_{2}$ in the experiment, showing that they act as dose-dependent antioxidants
(Figure 2). We had previously used the same DPPH measurement to detect radical scavenging (Hsu 2005) and had shown the relationship of antioxidant strengths among chlorophyll compounds $(50 \mu \mathrm{M}$ chlorophyll compounds versus $10 \mu \mathrm{M} \mathrm{H}_{2} \mathrm{O}_{2}$ ) were following the sequences as pheophorbide $>$ chlorophyllin $>$ chlorophyllide $=$ pheophytin $>$ chlorophyll (Hsu 2005). For each given natural chlorophyll compound there was no significant difference in antioxidant effect between the $a$ and $b$ forms.

Table 1. Effect of chlorophyll-related compounds upon human lymphocyte viability and DNA damage ${ }^{1}$.

\begin{tabular}{ccc}
\hline & ${\text { Viability }(\%)^{2}}$ & Comet assay (TM) \\
\hline Chlorophyll $a(50 \mu \mathrm{M})$ & $96.4 \pm 3.2$ & $103 \pm 22$ \\
Chlorophyll $b(50 \mu \mathrm{M})$ & $97.2 \pm 2.3$ & $102 \pm 25$ \\
Pheophytin $a(50 \mu \mathrm{M})$ & $98.3 \pm 2.4$ & $104 \pm 36$ \\
Pheophytin $b(50 \mu \mathrm{M})$ & $98.4 \pm 2.1$ & $102 \pm 26$ \\
DMSO (as solvent) & $96.8 \pm 2.5$ & $109 \pm 25$ \\
$\mathrm{H}_{2} \mathrm{O}_{2} 10 \mu \mathrm{M}$ & $99.4 \pm 2.4$ & $6386 \pm 803$ \\
Control & 100 & $103 \pm 21$ \\
\hline
\end{tabular}

${ }^{1}$ Mean $\pm \mathrm{SD} ;{ }^{2}$ Viability (measured by the MTS assay) was determined both prior to $(100 \%)$ and following chlorophyll-related compounds pretreatment. ${ }^{3}$ Mean Tail Moment (TM) was calculated by means of the comet assay.

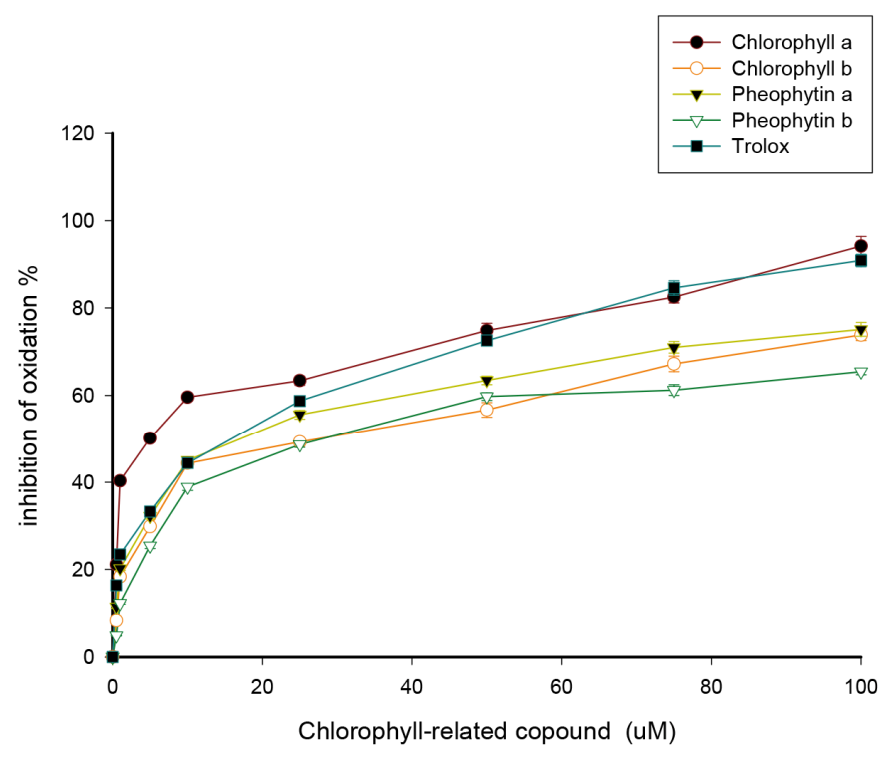

Oxidative inhibition of chlorophyll-related compounds extracts from spinach on TBARS assay

Figure 2. Prevention of oxidative DNA damage by chlorophylls and pheophytins. The results of comet assays following oxidation by $\mathrm{HO}_{2}$ are plotted as tail moments versus the concentrations of chlorophylls or pheophytins tested as antioxidants. The dose-dependent reduction in tail moment shows that fewer single stranded DNA breaks were caused by hyrdoxyl radicals when chlorophyll compounds were present. At all concentrations of chlorophylls and pheophytins tested, a significantly reduced level of DNA single stranded breaks was formed following $\mathrm{H}_{2} \mathrm{O}_{2}$ exposure $(p<0.05)$. It may also be seen from this figure that at 5 and $20 \mu \mathrm{M}$ concentrations all compounds tested had equal antioxidant capacities. 
In the Fenton reaction, $\mathrm{Fe}(\mathrm{II})$ catalyzes the decomposition of $\mathrm{H}_{2} \mathrm{O}_{2}$ to generate hydroxyl radicals, which can then damage DNA. Previously, we showed that the DNA was being hydroxylated during the comet assay, and that chlorophyll compounds prevent both the hydroxylation of DNA and the formation of single stand breaks in the DNA [12]. Two mechanisms could hypothetically account for the antioxidant effects of the chlorophyll compounds. The chlorophyll compounds could directly scavenge the hydroxyl free radicals generated from $\mathrm{H}_{2} \mathrm{O}_{2}$, or the chlorophyll compounds could chelate the Fe(II), preventing the Fenton reaction.

In order to test for free radical scavenging, chlorophyll and pheophytin were tested in a DPPH assay. Chlorophyll and pheophytin were able to reduce DPPH in a dose-dependent manner, showing that they can act as free radical scavengers (Figure 3); there was little difference between the activities of the $\mathrm{a}$ and $\mathrm{b}$ forms. The scavenging capacities of pheophytin did appear to be more pronounced than that of chlorophyll $(\mathrm{p}<0.05)$. The $50 \%$ inhibitory concentrations $\left(\mathrm{IC}_{50}\right)$ were about $161 \mu \mathrm{M}$ (pheophytin a), $198 \mu \mathrm{M}$ (pheophytin b), and greater than $200 \mu \mathrm{M}$ (chlorophylls a and b). Combined with our previous data [12], the relationship of free radical scavenging strengths ( $\mathrm{IC}_{50}$ values) among chlorophyll compounds is chlorophyllide $>$ chlorophyllin $>$ chlorophyll $>$ pheophytin $>$ pheophorbide. In general, this agrees with previous chlorophyll compound DPPH assay data [5,11], although their conditions and concentrations used were different.

We then tested the ability of different concentrations of chlorophylls or pheophytins to chelate $\mathrm{Fe}$ (II) from solution. As the concentration of the chlorophylls or pheophytins was increased, the ability of the Fe(II) to complex with ferrozine was decreased to more than half its original amount (Figure 4). We interpret this as evidence that the chlorophyll compounds chelated the Fe(II) atoms. In the case of the chlorophylls, this would require substitution of the $\mathrm{Fe}(\mathrm{II})$ for the $\mathrm{Mg}$ atom. This may explain why pheophytin was more active than chlorophyll in the assay. There was little difference in activity between the $\mathrm{a}$ and $\mathrm{b}$ forms.

We are not aware of previous reports exploring chlorophylls or pheophytins as antioxidant $\mathrm{Fe}(\mathrm{II})$ chelators. However, Arimoto-Kobayashi et al. [23] created an "Fechlorophyllin", a chlorophyll with Fe replacing the $\mathrm{Mg}$, structurally the same as our putative Fe-chelated chlorophyll or Fe-chelated pheophytin. Arimoto-Kobayashi et al. showed that their Fe-chlorophyllin could bind to a planar carcinogenic molecule and enhance its degradation rate. They speculate that the $\mathrm{Fe}$ atom makes the $\mathrm{Fe}$ chlorophyllin into an oxidative molecule that can both desmutagenically bind to planar carcinogen molecules and detoxify them by oxidization. This suggests that if dietary chlorophyll or pheophytin is spontaneously converted into Fe-chlorophyllin, not only would Fenton reactions be avoided, but also the resulting Fe-chlorophyllin would be a superior anti-carcinogen.

Recently, Nelson and Ferruzzi [24] synthesized "FePhe" out of pheophytin and Fe(II), which is essentially the same idea as Fe-chlorophyllin. Their purpose was to create an alternate bioavailable source of iron, although no dietary tests have been reported yet. It has been suggested [9] that in meals including red meat and

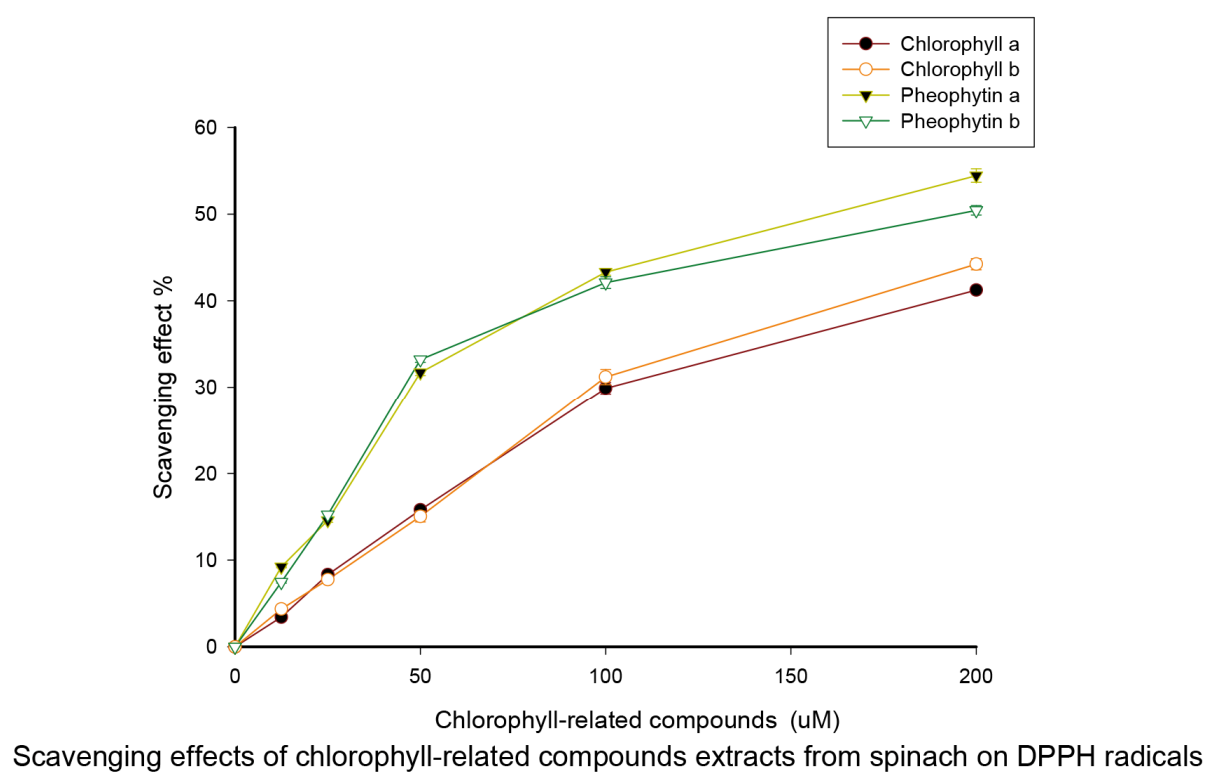

Figure 3. Chlorophylls and pheophytins scavenge the DPPH radical. The relative scavenging effect is plotted for different concentrations of test substances. All chlorophylls and pheophytins were able to scavenge the DPPH radical in a dose-dependent manner. 


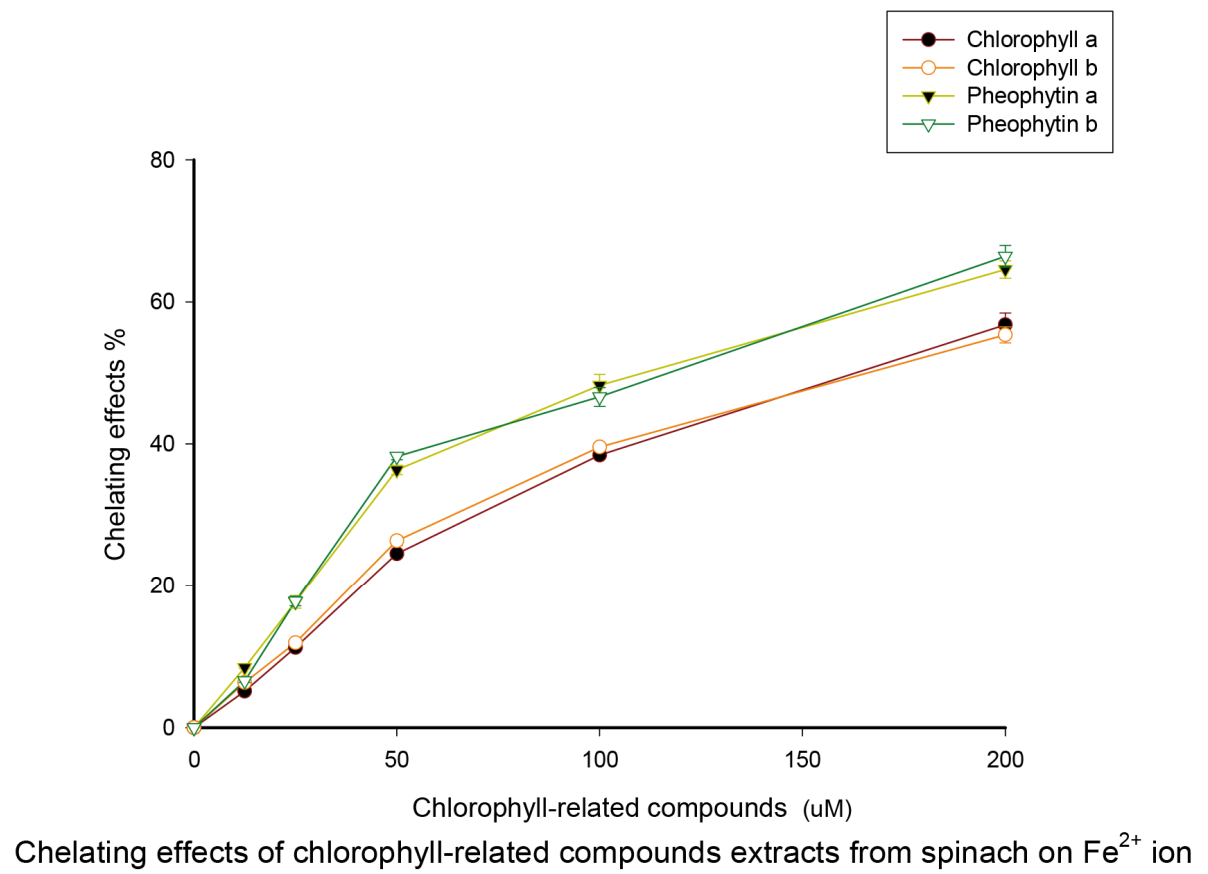

Figure 4. Inhibition of the Fe(II)-ferrozine reaction as a measure of Fe-chelation. The Fe(II) was pre-incubated with chlorophyll compounds before reacting with ferrozine. Data is presented as the proportional reduction in Fe(II)-ferrozine versus a control reaction (\% chelating effect). Pheophytins had significantly higher \% chelating effects than the chlorophylls $(p<0.05)$. The approximate $I_{50}$ values were: pheophytin a, $119 \mu \mathrm{M}$; pheophytin b, $123 \mu \mathrm{M}$; chlorophyll a, $171 \mu \mathrm{M}$; chlorophyll b 175 $\mu \mathrm{M}$.

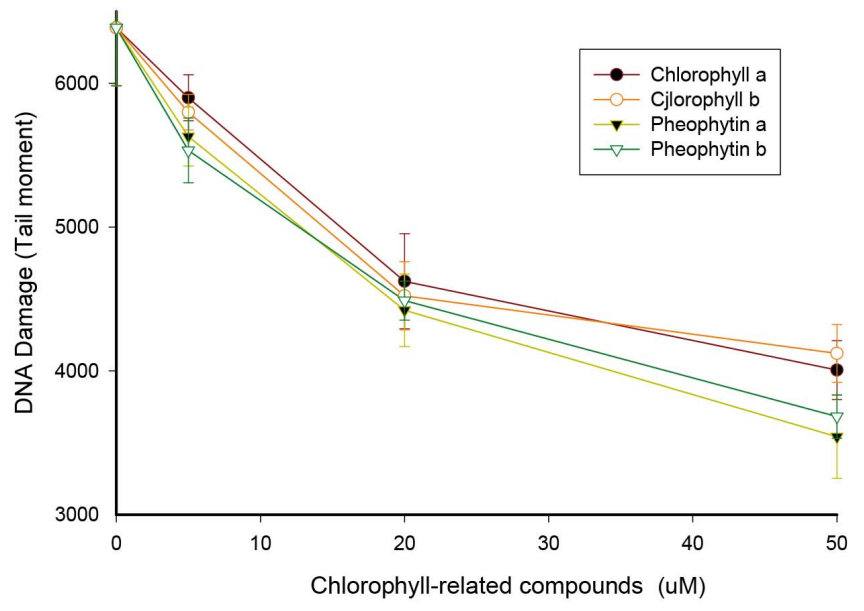

Effect of Chlorophyll-related compounds pretreatment on $10 \mathrm{uM}$ hydrogen peroxide-induced DNA damage in isolated human lymphocytes.

Figure 5. Chlorophylls and pheophytins inhibit lipid peroxidation. Peroxidation of low-density lipoprotein was catalyzed by $\mathrm{Cu}$. Addition of various concentrations of chlorophyll a, chlorophyll b, pheophytin a, or pheophytin b showed a dose-dependent antioxidant effect. The antioxidant trolox is included as a positive control.

green vegetables, the chlorophyll from the vegetables neutralizes the iron-containing heme from the meat. It is possible that chlorophyll compounds not only would absorb reactive $\mathrm{Fe}$ species from heme, but also would later transmit the $\mathrm{Fe}$ atoms as nutrients in a more benign fashion, in the same way as is intended for the engineered FePhe of Nelson and Ferruzzi. Clearly, further research into the interactions of $\mathrm{Fe}$ and chlorophyll compounds is warranted.

Following the evidence that chlorophyll and pheophytin act both as free radical scavengers and as $\mathrm{Fe}(\mathrm{II})$ chelators, we hypothesized that they might also be able to prevent the catalysis of lipid peroxidization. We performed a test of the ability of chlorophyll or pheophytin 
to prevent lipid peroxidation in an assay using a biological lipid (LDL) and $\mathrm{Cu}$, another atom which catalyzes Fenton reactions. The antioxidative effects of the chlorophyll compounds were determined by measuring the creation of thiobarbituric acid reactive substances (TBARS). Figure 5 shows that both chlorophyll and pheophytin inhibited copper-mediated LDL oxidative activity in a dose-dependent manner. Trolox, a synthetic water-soluble derivative of the antioxidant Vitamin E, was used as a positive control. The $50 \%$ inhibition $\left(\mathrm{I}_{50}\right)$ value, where a lower value of $\mathrm{I}_{50}$ indicates a higher antioxidant activity, for each compound was: trolox, $16 \mu \mathrm{M}$; chlorophyll a, $5 \mu \mathrm{M}$; chlorophyll b, $26 \mu \mathrm{M}$; pheophytin a, $17 \mu \mathrm{M}$; pheophytin b, $26 \mu \mathrm{M}$.

That these lipid peroxidation results are biologically relevant is supported by the research of de Vogel's et al. [9]. When rats were fed a diet containing heme, increased amounts of TBARS were found in their fecal water; however, when chlorophyll was added to this diet, the TBARS excretion returned to normal [9]. Based on our research, the mechanisms responsible for antioxidant effects on lipid peroxidation may involve both chelating of $\mathrm{Fe}$ or $\mathrm{Cu}$ atoms, and the scavenging of hydroxyl radicals, as well as possibly scavenging peroxy radicals, as suggested by Endo et al. [5].

The results of our research confirm that chlorophyll compounds are important health promoting dietary factors which can protect the body through multiple chemical mechanisms. In particular, we have shown that chlorophylls and pheophytins act as antioxidants to prevent oxidative DNA damage and lipid peroxidation both by chelating reactive ions and by scavenging free radicals.

\section{REFERENCES}

[1] G. Block, B. Patterson and A. Subar, "Fruit, Vegetables, and Cancer Prevention: A Review of the Epidemiological Evidence," Nutrition and Cancer, Vol. 18, No. 1, 1992, pp. 1-29. doi:10.1080/01635589209514201

[2] U. Harttig and G. S. Bailey, "Chemoprotection by Natural Chlorophylls in Vivo: Inhibition of Dibenzo[a,1]pyreneDNA Adducts in Rainbow Trout Liver," Carcinogenesis, Vol. 19, No. 7, 1998, pp. 1323-1326. doi:10.1093/carcin/19.7.1323

[3] K. I. Takamiya, T. Tsuchiya and H. Ohta, "Degradation Pathway(s) of Chlorophyll: What Has Gene Cloning Revealed?" Trends Plant Science, Vol. 5, No. 10, 2000, pp. 426-431. doi:10.1016/S1360-1385(00)01735-0

[4] M. G. Ferruzzi, M. L. Failla and S. J. Schwartz, “Assessment of Degradation and Intestinal Cell Uptake of Carotenoids and Chlorophyll Derivatives from Spinach Puree Using an in Vitro Digestion and Caco-2 Human Cell Model," Journal of Agricultural and Food Chemistry, Vol. 49, No. 4, 2001, pp. 2082-2089. doi:10.1021/jf000775r

[5] Y. Endo, R. Usuki and T. Kaneda, "Antioxidant Effects of Chlorophyll and Pheophytin on the Autoxidation of Oil in the Dark II. The Mechanism of Antioxidative Action of Chlorophyll," Journal of the American Oil Chemists' Society, Vol. 62, No. 9, 1985, pp. 1387-1390. doi:10.1007/BF02545965

[6] N. Tachino, D. Guo, W. M. Dashwood, S. Yamane, R. Larsen and R. Dashwood, "Mechanisms of the in Vitro Antimutagenic Action of Chlorophyllin against Benzo[a]pyrene: Studies of Enzyme Inhibition, Molecular Complex Formation and Degradation of the Ultimate Carcinogen," Mutation Research, Vol. 308, No. 2, 1994, pp. 191-203. doi:10.1016/0027-5107(94)90154-6

[7] S. Chernomorsky, A. Segelman and R. D. Poretz, "Effect of Dietary Chlorophyll Derivatives on Mutagenesis and Tumor Cell Growth," Teratogenesis, Carcinogenesis, and Mutagenesis, Vol. 19, No. 5, 1999, pp. 313-322. doi:10.1002/(SICI)1520-6866(1999)19:5<313::AID-TCM 1>3.0.CO;2-G

[8] P. A. Egner, J. B. Wang, Y. R. Zhu, B. C. Zhang, Y. Wu, Q. N. Zhang, G. S. Qian, S. Y. Kuang, S. J. Gange, L. P. Jacobson, K. J. Helzlsouer, G. S. Bailey, J. D. Groopman and T. W. Kensler, "Chlorophyllin Intervention Reduces Aflatoxin-DNA Adducts in Individuals at High Risk for Liver Cancer," Proceedings of the National Academy of Sciences, Vol. 98, No. 25, 2001, pp. 14601-14606. doi:10.1073/pnas. 251536898

[9] J. de Vogel, D. S. Jonker-Termont, M. B. Katan and R. van der Meer, "Natural Chlorophyll But Not Chlorophyllin Prevents Heme-Induced Cytotoxic and Hyperproliferative Effects in Rat Colon," Journal of Nutrition, Vol. 135, No. 8, 2005, pp. 1995-2000.

[10] M. T. Simonich, P. A. Egner, B. D. Roebuck, G. A. Orner, C. Jubert, C. Pereira, J. D. Groopman, T. W. Kensler, R. H. Dashwood, D. E. Williams and G. S. Bailey, "Natural Chlorophyll Inhibits Aflatoxin B1-Induced Multi-Organ Carcinogenesis in the Rat," Carcinogenesis, Vol. 28, No. 6, 2007, pp. 1294-1302. doi:10.1093/carcin/bgm027

[11] U. Lanfer-Marquez, R. Barros and P. Sinnecker, "Antioxidant Activity of Chlorophylls and Their Derivatives," Food Research International, Vol. 38, No. 8, 2005, pp. 885-891. doi:10.1016/j.foodres.2005.02.012

[12] C. Y. Hsu, C. M. Yang, C. M Chen., P. Y. Chao and S. P. $\mathrm{Hu}$, "Effects of Chlorophyll-Related Compounds on Hydrogen Peroxide Induced DNA Damage within Human Lymphocytes," Journal of Agricultural and Food Chemistry, Vol. 53, No. 7, 2005, pp. 2746-2750. doi:10.1021/jf048520r

[13] M. Sato, K. Imai and T. Murata, "Effect of Sodium Copper Chlorophyllin on Lipid Peroxidation: The Antioxidative Activities of the Commercial Preparations of Sodium Copper Chlorophyllin," Yakugaku Zasshi, Vol. 100, No. 5, 1980, pp. 580-584.

[14] J. P. Kamat, K. K. Boloor and T. P. Devasagayam, "Chlorophyllin as an Effective Antioxidant against Membrane Damage in Vitro and ex Vivo," Biochim Biophys Acta, Vol. 1487, No. 2-3, 2000, pp. 113-127. doi:10.1016/S1388-1981(00)00088-3

[15] J. W. Fahey, K. K. Stephenson, A. T. Dinkova-Kostova, P. A. Egner, T. W. Kensler and P. Talalay, "Chlorophyll, Chlorophyllin and Related Tetrapyrroles Are Significant 
Inducers of Mammalian Phase 2 Cytoprotective Genes," Carcinogenesis, Vol. 26, No. 7, 2005, pp. 1247-1255. doi:10.1093/carcin/bgi068

[16] S. Kapiotis, M. Hermann, M. Exner, H. Laggner and B. M. Gmeiner, "Copper- and Magnesium Protoporphyrin Complexes Inhibit Oxidative Modification of LDL Induced by Hemin, Transition Metal Ions and Tyrosyl Radicals," Free Radical Research, Vol. 39, No. 11, 2005, pp. 1193-1202. doi:10.1080/10715760500138981

[17] C. M. Yang, K. W. Chang, M. H. Yin and H. M. Huang, "Methods for the Determination of the Chlorophylls and Their Derivatives," Taiwania, Vol. 43, No. 2, 1998, pp. 116-122.

[18] V. Schumasker and D. Puppione, "Sequential Flotation Ultracentrifugation," In: J. Segrest and J. Albers, Eds., Methods in Enzymology, Academic Press, San Diego, Vol. 128, 1986, pp. 155-170.

[19] N. P. Singh, M. T. McCoy, R. R. Tice and E. L. Schneider, "A Simple Technique for Quantitation of Low Levels of DNA Damage in Individual Cells," Experimental Cell Research, Vol. 175, No. 1, 1988, pp. 184-191. doi:10.1016/0014-4827(88)90265-0

[20] T. C. Dinis, V. M. Maderia and L. M. Almeida, "Action of Phenolic Derivatives (Acetaminophen, Salicylate, and
5-Aminosalicylate) as Inhibitors of Membrane Lipid Peroxidation and as Peroxyl Radical Scavengers," Arch Biochem Biophys, Vol. 315, No. 1, 1994, pp. 161-169. doi:10.1006/abbi.1994.1485

[21] B. Wallin, B. Rosengren, H. G. Shertzer and G. Camejo, "Lipoprotein Oxidation and Measurement of Thiobarbituric Acid Reacting Substances Formation in a Single Microtiter Plate: Its Use for Evaluation of Antioxidants," Analytical Biochemistry, Vol. 208, No. 1, 1993, pp. 10-15. doi:10.1006/abio.1993.1002

[22] K. Yagi, “Assay for Blood or Plasma,” In: L. Packer, Ed., Methods in Enzymology, Oxygen Radical in Biological System, Academic Press, New York, 1984, pp 328-331. doi:10.1016/S0076-6879(84)05042-4

[23] S. Arimoto-Kobayashi, N. Inada, H. Nakano, H. Rai and H. Hayatsu, "Iron-Chlorophyllin-Mediated Conversion of 3-Hydroxyamino-1-methyl-5H-pyrido[4,3-b]indole (Trp$\mathrm{P}-2(\mathrm{NHOH}))$ into Its Nitroso Derivative," Mutation Research, Vol. 400, No. 1-2, 1998, pp. 259-269. doi:10.1016/S0027-5107(98)00033-5

[24] R. E. Nelson and M. G. Ferruzzi, "Synthesis and Bioaccessibility of Fe-Pheophytin Derivatives from Crude Spinach Extract," Journal of Food Science, Vol. 73, No. 5, 2008, pp. H86-H91. doi:10.1111/j.1750-3841.2008.00783.x 